\title{
Una década de retos y transformaciones en el ejercicio de la divulgación del conocimiento
}

\author{
Bibiana Vélez Medina* \\ María Angélica Ortiz Salazar** \\ Ana María Mosquera Ayala***
}

* $\mathrm{PhD}$ en Educación, Vicerrectora Académica , Editora Revista Sophia. Universidad La Gran Colombia Seccional Armenia.

**Mg. en Educación, Directora de Investigaciones Universidad La Gran Colombia Seccional Armenia.

*** Comunicadora Social. Líder de Producción Bibliográfica, Universidad La Gran Colombia Seccional Armenia

$\mathrm{E}$ n el ámbito de la difusión y la visibilidad del conocimiento científico, las revistas seriadas son el eje dinamizador del sistema de comunicación de los resultados de procesos investigativos al mundo académico. El propósito principal es que el lector utilice la información publicada para incorporar, en distintos contextos, el análisis de resultados, metodologías y conclusiones obtenidas por otros académicos, de tal manera que, se facilite la aplicación y la construcción de nuevos conocimientos. Por supuesto, si quiere alcanzarse el estatus de rigor científico, estas revistas deben adoptar sistemas transparentes, exigentes y altamente calificados de edición, acogiéndose a las políticas establecidas por las instituciones reguladoras a nivel nacional e internacional, a fin de lograr una legítima visibilidad.

En el caso colombiano, Publindex es el organismo encargado de registrar y reconocer las revistas científicas. A partir de su implementación en 2001 se empezó a vivir un proceso de transición en la difusión y divulgación del conocimiento científico, al diseñar modelos de evaluación con altos criterios de clasificación agrupados en cuatro categorías C, B, A2 y A1 que son empleados para medir tanto la calidad editorial, como la estabilidad y visibilidad. (Publindex 2013)

Los criterios de clasificación exigidos por Publindex han configurado los planes de trabajo de numerosos equipos editoriales que han logrado durante estos años la inclusión de sus revistas. Sin embargo, un elevado porcentaje de estas no ascienden en el escalafón entre cada clasificación. Así lo asevera Publindex:

Si bien es cierto que en 10 años de conformado el servicio de indexación, hay un importante crecimiento de la producción científica nacional, también lo es, que la mayoría de publicaciones integradas en el IBN Publindex, carecen de visibilidad e impacto internacional y son de orden endogámico, evidenciado, en el bajo porcentaje de revistas nacionales indexadas en índices de citación que miden impacto. Actualmente, 4.72\% (22 revistas) cuentan con factor de impacto y el 53.6\% (250 revistas) en categoría C son de caracter endogámico. (Publindex, 2013). 
Desde el 2002 Publindex ha clasificado en sus 4 categorías más de 500 revistas colombianas editadas por instituciones académicas en diferentes áreas del conocimiento. En adelante, se hará un recorrido por el camino que han trazado en el periodo de una década las revistas colombianas de educación, seguido de una breve reseña de la revista Sophia.

Dentro de los registros del Índice Bibliográfico Nacional Publindex, la revista más antigua de educación es La Revista Colombiana de Educación, editada desde 1978 por la Universidad Pedagógica Nacional, fue pionera en facilitar el intercambio de ideas entre grupos de estudio, mediante la divulgación de trabajos inéditos de investigación. Su trabajo ha estado orientado principalmente a la divulgación de trabajos de investigación educativa y a estudios teóricos sobre el campo de la educación y la pedagogía. Actualmente se encuentra indexada en la categoría A2 y está registrada en Publindex desde el segundo semestre del año 2004. A este mismo propósito se sumaron otras revistas de educación, las cuales alcanzaron calidad en todos los parámetros de la actividad editorial y lograron posicionar sus títulos entre los más prestigiosos del país.

Entre 2004 y 2015 se han incluido en Publindex 20 revistas registradas en el área de educación. En el periodo 2004-2008 fueron reconocidas las siguientes: Revista Colombiana de Educación, Educación y Educadores, Historia de la educación latinoamericana, Pedagogía y saberes, y, Sophia. Las 14 restantes fueron incluidas en el índice entre el 2009 y 2015. A la fecha, solo el $25 \%$ del total de las revistas registradas desde el 2004, muestran un ascenso en el escalafón que definió Publindex, solo 5 de ellas han alcanzado estándares de calidad editorial para pertenecer a la categoría A2 entre estas la Revista Sophia de La Universidad La Gran Colombia Seccional Armenia. Ver gráfica 1.

La gráfica 1 se dividió en 2 momentos de observación, en el A se evidencia la categoría actual y su relación con la fecha de ingreso a Publindex. Así mismo en la B se registra el ascenso de las cinco mejores revistas escalafonadas en el país.

\section{Grafica 1.}

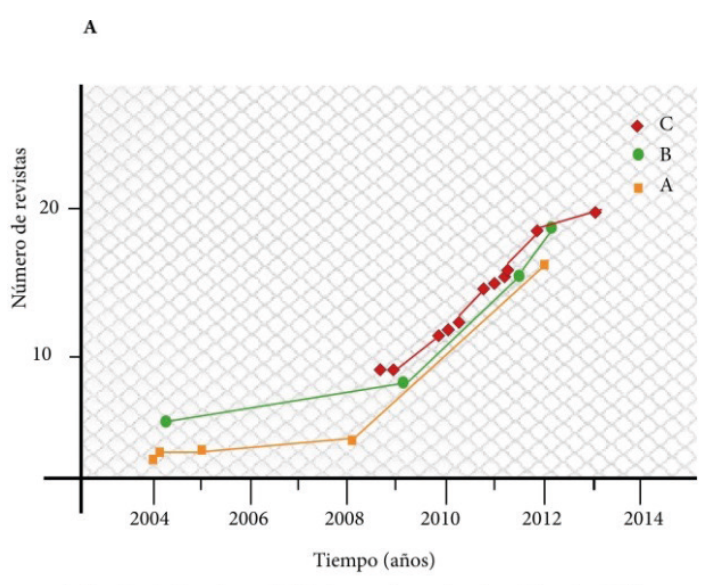

A. Revistas indexadas en Publindex en el area de educación entre 2004 y 2014. Relación entre la categoría actual y la fecha de indexación.

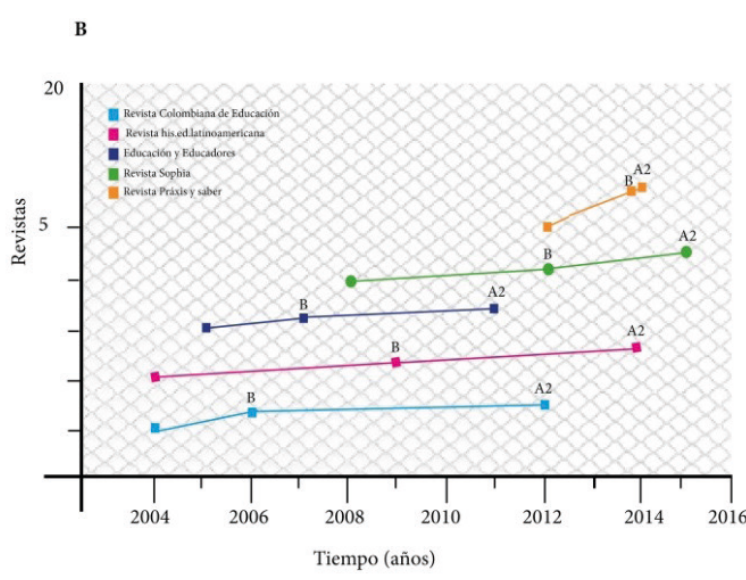

B relación de las revistas A2 y el tiempo que tardaron en alcanzar cada catgoría desde su fecha de inclusión.

Fuente: Elaboración propia a partir de datos de IBN Publindex-Colciencias, 2015. 
La revista Sophia es una publicación editada por la Universidad La Gran Colombia Seccional Armenia, orientada a la divulgación de artículos inéditos resultado de investigaciones desarrolladas por la comunidad académica en el área de educación. Su primera publicación se lanzó en el año 2005 con una edición de seis artículos de investigación y un editorial. En sus inicios Sophia publicaba ediciones multidisciplinares, pero, posteriormente concentró su área disciplinar al ámbito de la educación y cinco años después de su lanzamiento, en el año 2008 fue reconocida por Publindex en categoría C.

Desde entonces, se han adoptado prácticas editoriales rigurosas con el fin de dar cumplimiento a los requisitos esenciales de calidad científica, dentro de los cuales se destacan: publicar artículos de alta calidad, promover la discusión académica, y fomentar la internacionalización del conocimiento a través de la inclusión de la revista en bases de datos internacionales. Todas estas prácticas posibilitaron el ascenso de la revista a categoría B en la primera clasificación emitida por Publindex en el año 2012.

En sintonía con estos logros, a finales del año 2013 el histórico de publicaciones de Sophia, apareció por primera vez en formato electrónico a través del Open Journals Systems. Es importante mencionar que, esta plataforma fue diseñada por el grupo Public Knowledge Project de Canadá para facilitar el desarrollo de publicaciones de acceso libre revisadas por pares, cuenta con la infraestructura técnica para la presentación en línea de artículos, y también para la gestión del flujo editorial por completo. Este desarrollo fue creado con el propósito de expandir y mejorar el acceso a la investigación académica, se encuentra disponible sin costo alguno para publicaciones periódicas, con el fin de convertir la modalidad de libre acceso en una opción favorable para un mayor número de publicaciones. (López, 2012).

Con la incursión de Sophia en la web, la revista se unió al movimiento Open Acces, definido por Bravo, (2014) como una nueva manera de difundir la producción académica, en la cual el acceso libre debe ser garantizado por la revista sin restricciones al momento de su publicación en línea. El origen y desarrollo de este movimiento se fundamenta en 2001, cuando el Open Society Institute (OSI), Declara el Open Acces como una propuesta para conseguir el acceso libre a los artículos de investigación por internet. La declaración se realiza con base en dos pilares básicos:

1. Aboga por la supresión de barreras que limiten el acceso al fruto de la investigación como un bien universal al que todos tienen derecho, permitiendo a cualquier usuario leer, descargar, copiar, distribuir, imprimir, buscar o usar con cualquier propósito legal, sin ninguna barrera financiera, legal o técnica fuera de lo que es acceder a Internet.

2. Proporcionar a los autores y a su obra un nuevo escenario, donde difundirla y darle mayor visibilidad e impacto. La única limitación en cuanto a reproducción, distribución y copyright será dar a los autores el control sobre la integridad de sus trabajos y el derecho de ser adecuadamente reconocidos y citados. (Montano, 2009).

Estos desarrollos aumentaron la demanda de articulistas interesados en publicar en Sophia. A partir del año 2014, el Comité Editorial declara su periodicidad semestral, lo cual dispara el índice de recepción y la tasa de rechazo. Para el 2015, con la puesta en marcha de un plan de trabajo para incrementar la visibilidad y el impacto, se logró la inclusión de la revista en distintos acervos electrónicos como: Scielo Colombia, Redalyc-México y Dialnet-España, como consecuencia de ello la revista asciende a categoría A2 en Publindex.

A lo largo de una década, los resultados de estas distintas transformaciones han empezado a generar impacto, la publicación de dos ediciones en inglés, el ingreso a bases de datos e índices, la diversidad geográfica de nuestros autores y editores, así como las citas recibidas con buen índice de inmediatez durante el año pasado, dan cuenta de ello con suficiencia. Actualmente, la proyección de la revista gira alrededor de dos ejes fundamentales para su fortalecimiento: el primero, la indexación de sus contenidos en Scopus, la mayor base de resúmenes y referencias bibliográficas de literatura científica revisadas por pares y, el segundo, asumir 
los cambios que se avecinan en el nuevo modelo que propone Publindex. Ambos casos se constituyen en un reto de crecimiento e internacionalización.

Finalmente, que sea esta editorial una invitación a toda la comunidad académica para leer nuestros contenidos y para apropiarse de los desafíos, las problemáticas y los avances en el área de la educación. Nuestro compromiso es cautivar al lector, de manera que encuentre en su paso por la revista una experiencia enriquecedora para sus procesos académicos e investigativos.

\section{Referencias Bibliográficas}

Bravo, L E. (2014). De la imprenta a Scielo y Pubmed Central. Colomb. Méd. 45(1):5-6.

López, M. (2012). Open journal system (ojs). Una herramienta de gestión editorial en línea. Archivos Venezolanos de Puericultura y Pediatría, 75(2), 34. Recuperado de http://www.redalyc.org/ articulo.oa? id=367937044001

Montano, B. (2009). Acceso abierto (open access), un modelo necesario de comunicación científica. Pediatría Atención Primaria, Abril-Junio, 299-311.

Publindex (2013). Documento guía para el servicio permanente de indexación de revistas seriadas de ciencia tecnología e innovación colombianas del Departamento Administrativo de Ciencia, Tecnología e Innovación. Colciencias. Bogotá Recuperado de: http://publindex.colciencias.gov.co:8084/ publindex/EnIbnPublindex/resultados.do 